\title{
SYNTHESIS AND CHARACTERIZATION OF POLY(VINYL ALCOHOL)-HYALURONIC ACID BLENDED HYDROGEL MEMBRANES
}

\author{
Elbadawy, A. Kamoun ${ }^{a}$; Alaa Fahmy ${ }^{\text {b }}$, R.A.El-Eisawy ${ }^{\text {b }}$; Abdelhai Farag ${ }^{\text {b }}$; A.M.Naser ${ }^{\text {b }}$; \\ Basem, Kh.El-Damhougy ${ }^{b}$ \\ a Polymer Materials Research Department, Advanced Technology \& New Materials Research Institute (ATNMRI), City of Scientific \\ Research and Technological Applications (SRTA-City), New Borg Al-Arab City, P.O. Box 21934, Alexandria, Egypt \\ b Faculty of Science, Al-Azhar University, Egypt
}

\section{ABSTRACT}

Poly(vinyl alcohol)PVA is a hydrophilic polymer and water soluble . It is used in many biomedical and pharmaceutical applications, due to its advantages such as: non-toxic, non-carcinogenic, and biodegradable characteristics with the ease of processing. Physically cross-linked hydrogel membranes composed of different amounts of hyaluronic acid (HA) blend with (PVA) were prepared by freeze-thawing method. This freezing-thawing cycle was repeated for three consecutive cycles. Properties of (PVA-HA) hydrogel membrane such as gel fraction, swelling, mechanical properties(tensile strength, elongation to break),degradation and protein adsorption were investigated. With the increasing of HA content, the gel fraction, the maximum tensile strength and elongation at break $(\%)$ of (PVAHA) hydrogel membranes were decreased. Furthermore, with the increase of HA content, the swelling, the protein adsorption and the hydrolytic degradation of PVA-HA hydrogel membrane were increased.After soaking of hydrogel membrane for three days in phosphate buffer saline (PBS), the maximum weight loss of PVA-HA hydrogel membranes ranged between $18 \%$ and $70 \%$ according to HA content, this indicates that they are biodegradable.

Key words : Poly(vinyl alcohol), Hyaluronic acid, Hydrogel membranes, Freezing- thawing.

\section{1-Introduction}

In recent years, there has been an increasing interest in physically cross-linked gels (Peppas \& Scott, 1992 ;De Jong et al., 2001; Molina et al., 2001; Berger et al., 2004 and Van Tomme et al., 2005). The main reason is to avoid the use of chemical cross-linking agents which are not only often toxic compounds but also can affect the integrity of the substances when entrapped (e.g., proteins, cells). To create physically cross-linked gels, there are different methods such as ionic interaction (Berger et al., 2004 and Van Tomme et al., 2005), amphiphilic block and graft copolymers (Molina et al., 2001), stereocomplex formation (De Jong et al., 2001 and Hennink et al.,2004), freezing-thawing (Yokoyama et al., 1985; Peppas \& Scott, 1992 and Hassan \& Peppas, 2000). PVA holds tremendous promise as a hydrogel-forming polymer via crystallization owing to its non-toxic and hydrophilic nature (Peppas, 1987). Different methods have been reported in preparation of PVA-based hydrogels including radiation cross-linking (Yoshii et al., 1999 and Park \& Changnho, 2003;), chemical reaction with glyoxal (Teramoto et al., 2001), bifunctional reagents, e.g., glutaraldehyde (Peppas \& Benner, 1980 and Dai \& Barbari, 1999), or borates (Korsmeyer \& Peppas, 1981). Aqueous solution of PVA would be eventually transformed to a low strength gel upon long storage at room temperature however; this does not meet many applications' requirements where mechanical properties are important. In a method, pioneered by Peppas et al. (1975), semi-crystalline gels were prepared by exposing PVA aqueous solution to repeated freezing and thawing cycles which induced crystallization and resulted in a network structure with the quasi-permanent crystallites which act as physical cross-linking sites in the network. This method is the preferred route to prepare an 
"ultrapure" network without the using any toxic cross-linking agents with tunable mechanical properties (Yokoyama et al., 1985). Mechanical properties of the gel increase with the temperature, number of freezing-thawing cycles, polymer solution concentration and its molecular weight hence; different mechanical properties and erosion time up to six monthes were obtained (Hassan \& Peppas, 2000).

PVA as a hydrophilic polymer is water soluble (Briscoe et al., 2000). It is used in many biomedical and pharmaceutical applications, due to its advantages such as: non-toxic, non-carcinogenic, bio-adhesive and biodegradable characteristics with the ease of processing (Wensheng et al., 2002).

Hyaluronic acid (HA) is a naturally-occurring linear polysaccharide comprised of $\beta$ 1,4-linked D-glucuronic acid ( $\beta$-1,3) N-acetyl-D-glucosamine disaccharide units, and it is the only non-sulfated glycosaminoglycan (GAG) in the extracellular matrix (ECM) of all higher animals. This polyanionic polymer has unique physicochemical properties and distinctive biological functions (Laurent et al., 1995).

Some recent biomedical applications of HA include ophthalmic surgery, arthritis treatment, scaffolds for wound healing, tissue engineering, drug delivery (Saettone et al 1994) and components for implant materials (Candy \& Sharma,1990; Okamoto et al., 1992 and Hong et al., 1993).

Hydrogles being used as basic materials for manufacturing of wound dressings were invented in 1989 by Rosiak et al. However, some of the hydrogel dressings, due to their low strength and elasticity, did not satisfy the ideal dressing requirements, viz, they might stick to the wound surface or crushed under high stresses (Yoshii et al., 1999) .

The present work is designed to prepare blended hydrogel membranes (PVA-HA) by freezing-thawing method as membranes with good strength and elasticity to be compatible in biomedical application. This is the first time to prepare these membranes by this method for wound dressing.

\section{2-. EXPERIMENTAL}

\subsection{Materials}

PVA (typically average $\mathrm{Mw}=72,000 \mathrm{~g} / \mathrm{mol}$; $98.9 \%$ hydrolyzed) was obtained from Biochemica, Germany. HA(was purchased from shanghaijiaoyuan industry co, ltd, china), Ascorbic acid(MW=176.13 g/mol; 99\% hydrolyzed). Distilled water was used throughout this work.

\subsection{Preparation of hydrogel membranes}

PVA-HA hydrogel membranes were prepared by freezing- thawing (F-T) cycle according to the reported procedure of Peppas and Stauffer (1991). Briefly, aqueous solution containing 5\% (w/v) PVA, $1 \%(\mathrm{w} / \mathrm{v}) \mathrm{HA}$ and $0.3 \%(\mathrm{w} / \mathrm{v})$ of ascorbic acid (AA) were carefully dissolved in distilled water. Different proportions of PVA and HA contents $(0 \%, 10 \%, 20 \%, 30 \%, 40 \%$, and 50\%) solutions were mixed, sonicating, and vortexing for one hour. Proper amounts of this mixture were poured in Petri dishes, followed by freezing at $-20{ }^{\circ} \mathrm{C}$ for 18 hours and thawing for 6 hours at $25{ }^{\circ} \mathrm{C}$ for one, two, and three continuous cycles. 


\section{3- Characterizations}

\subsection{1-Gel fraction}

The pieces of PVA-HA hydrogel membrane samples $2 \times 2(\mathrm{~cm})$ were dried for 6 hrs at $50^{\circ} \mathrm{C}$ in an oven and weighted $(W o)$. They were soaked in distilled water into Petri dishes for $24 \mathrm{hrs}$ up to a constant weight and taken out from Petri dishes in order to remove the soluble parts. The gels were dried again at $50^{\circ} \mathrm{C}$ in an oven and weighted again $(W e)$. The gel fraction percentage was calculated by the following equation (Yoshii et al., 1999 and Ajji et al., 2005):

$$
\text { Gel fraction }(G F \%)=(\text { We/ WO }) \times 100
$$

Where $\left(W_{0}\right)$ and $(W e)$ are the weights of hydrogel samples dried for $6 \mathrm{hrs}$ at $50{ }^{\circ} \mathrm{C}$ before and after soaking, respectively.

\subsection{2-Water uptake}

In order to measure the water uptake of PVA-HA hydrogel membranes, the membrane samples were cut into $2 \times 2(\mathrm{~cm})$ pieces and dried at $50{ }^{\circ} \mathrm{C}$ in an oven for $6 \mathrm{hrs}$, the weight of dried sample were determined (We). The dried samples were soaked indistilled water, maintained and incubated at $37^{\circ} \mathrm{C}$, then weighted $(W s)$ at specific interval times. The water uptake of PVA-HA hydrogel membranes was determined using the following Eq.

(2) Yang et al. (2008):

$$
\text { Water uptake }(\%)=(W s-W e / W e) \times 100
$$

Where $(W s)$ is the weight of swelled sample and $(W e)$ is the weight of dry sample.

\subsection{3-Mechanical properties}

The maximum tensile strength and the elongation to break of PVA-HA blend hydrogel membranes have been conducted using a tensile test machine (model: AG-I / $50 \mathrm{~N}$ - $10 \mathrm{KN}, J a p a n)$. PVA- HA membranes were cut into specific adog-bone shape $(5 \mathrm{~cm}$ long, $1.5 \mathrm{~cm}$ wide at the ends and $1 \mathrm{~cm}$ in the middle). The analysis was performed at stretching rate $10 \mathrm{~mm} / \mathrm{min}$. The thickness of membrane samples were measured with an electronic digital micrometer before examination (Alencar et al., 2003).

\subsection{4-Protein adsorption study}

The amount of adsorbed bovine serum albumin (BSA) was detected by UV-visible spectrophotometer. In order to establish the relationship between the visible absorbance of BSA at $630 \mathrm{~nm}$ and the concentration of BSA, a calibration curve was drawn for standard solution of BSA ranging from 3.1-60 mg/ml. All standard solutions were prepared with distilled water. From the calibration curve a study was made restricting the curve to the linear part that followed linear part that followed Beer's law

$$
A=a c L
$$

Where A the absorbance, $\mathrm{c}$ is the concentration, $\mathrm{a}$ is a proportionality constant and $\mathrm{L}$ is the path-length which is constant (Queiroz et al., 2001).

Pieces of PVA- HA hydrogel membranes cut into $1 \times 1(\mathrm{~cm})$ were immersed in $10 \mathrm{ml}$ phosphate buffer saline (PH 7.4), and incubated at $37{ }^{\circ} \mathrm{C}$ for $24 \mathrm{hrs}$ until reach to equilibrium swelling weight.

The swollen hydrogel pieces were transferred to buffer solution containing BSA (30 $\mathrm{mg} / \mathrm{ml}$ ) and shacked for $4 \mathrm{hrs}$ at $37{ }^{\circ} \mathrm{C}$. After protein adsorption, the hydrogel pieces were gently removed. The protein adsorption for each sample were calculated by the difference 
between protein concentrations before and after immersing hydrogel pieces in protein/ phosphate buffer solution using albumin reagent kit ( absorbance range at $630 \mathrm{~nm}$ ), this procedure has been adapted and modified from the procedure of Lin et al. (2006).

\subsection{5- Hydrolytic degradation}

The degradation activities were determined by the hydrolytic degradation method (Xiao and Zhou, 2003). This method is based on gravimetric determination study of the weight loss $\%$ of the gel. Procedure: dry 2 x $2(\mathrm{~cm})$ membrane samples were weighed and immersed in $10 \mathrm{ml}$ phosphate-buffer saline (PBS) $(0.1 \mathrm{M}, \mathrm{pH} 7.4)$ at $37^{\circ} \mathrm{C}$. The samples were removed at timed intervals, blotted with soft paper to remove surface water, dried at ambient temperature and weighed.

\section{RESULTS AND DISCUSSION}

\section{1-Gel fraction}

Fig. (1) Shows the gel fraction of the PVA hydrogels membrane with different HA content. The results clearly indicated that with the increase of HA content, the gel fraction of the hydrogel membrane decreased. During F-T cycles, the cross-linking strength of HA was weaker than that of PVA, even though HA formed a cross-linking bond with PVA in the gel. Generally, as the gel fraction decreased, the strength of the gel was weakened (Ajji $\boldsymbol{e t}$ al., 2005 and Kim et al., 2008). There fore, HA could be used to control the strength of hydrogel because it reduced the cross-linking reaction and, consequently, the gelation process. This is in agreement with Maolin et al. (2002) on their study at PVA-starch blended hydrogels, Long et al. (2003) on PVA-carboxymethylated chitosan blended hydrogels .

\section{2-Water uptake}

As shown in Fig. (1) the water uptake of PVA hydrogel membrane increases with increasing HA content in hydrogel membranes. This due to, the high hydrophilicity of HA in PVA film which increases the water uptake character of the studied hydrogel. This coincide with Hwang et al. (2010) and Abou El-Enin (2013). They found that the swelling of PVA-dextran and PVA-alginate blended hydrogel membranes increased with increasing dextran and alginate contentes respectevily. 


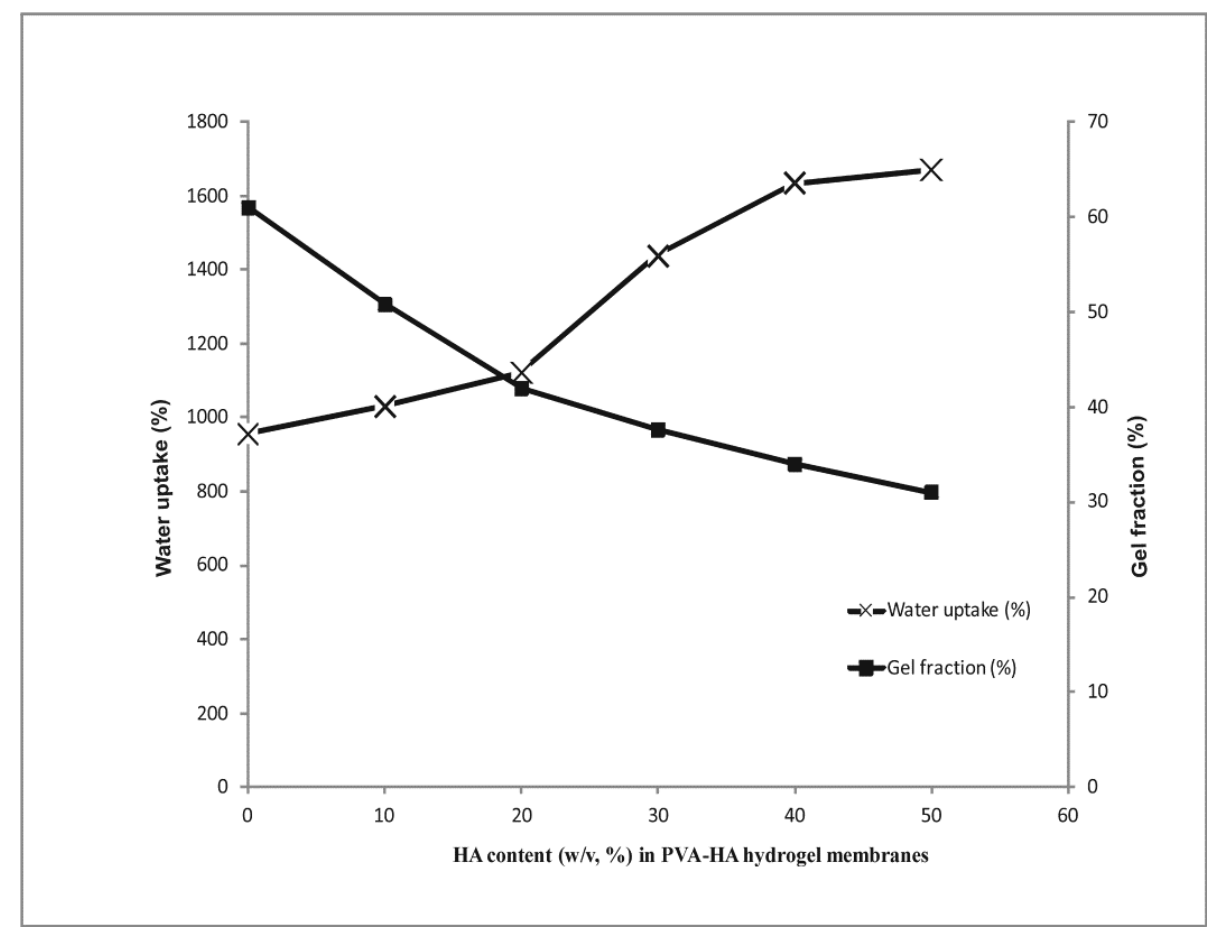

Fig. 1- Effect of HA content in PVA hydrogel membranes on gel fraction and water uptake(\%).

\section{3-mechanical properties}

To investigate the influence of HA on the mechanical properties of the hydrogels, their tensile strength and elongation to break were evaluated (Fig.2 ).The maximum tensile strength and elongation at break of hydrogel membranes decreases with increasing HA content. As HA was blended with PVA, the cross-linking density of the gel was decreased. These results are coincide with that of Rosiak et al. (2001). They referred that the maximum tensile strength of PVA hydrogel decreased with increasing blend materials due to decreased cross-linking density. Hwang et al. (2010) demonstrated that the maximum tensile strength of PVA hydrogel has sharply decreased with increasing dextran portions in the hydrogel and Abou El-Enin (2013) who reported that the maximum tensile strength and elongation at break of PVA-HES hydrogel membranes, sharply decreased with increasing hydroxyethylstarch (HES) contents. 


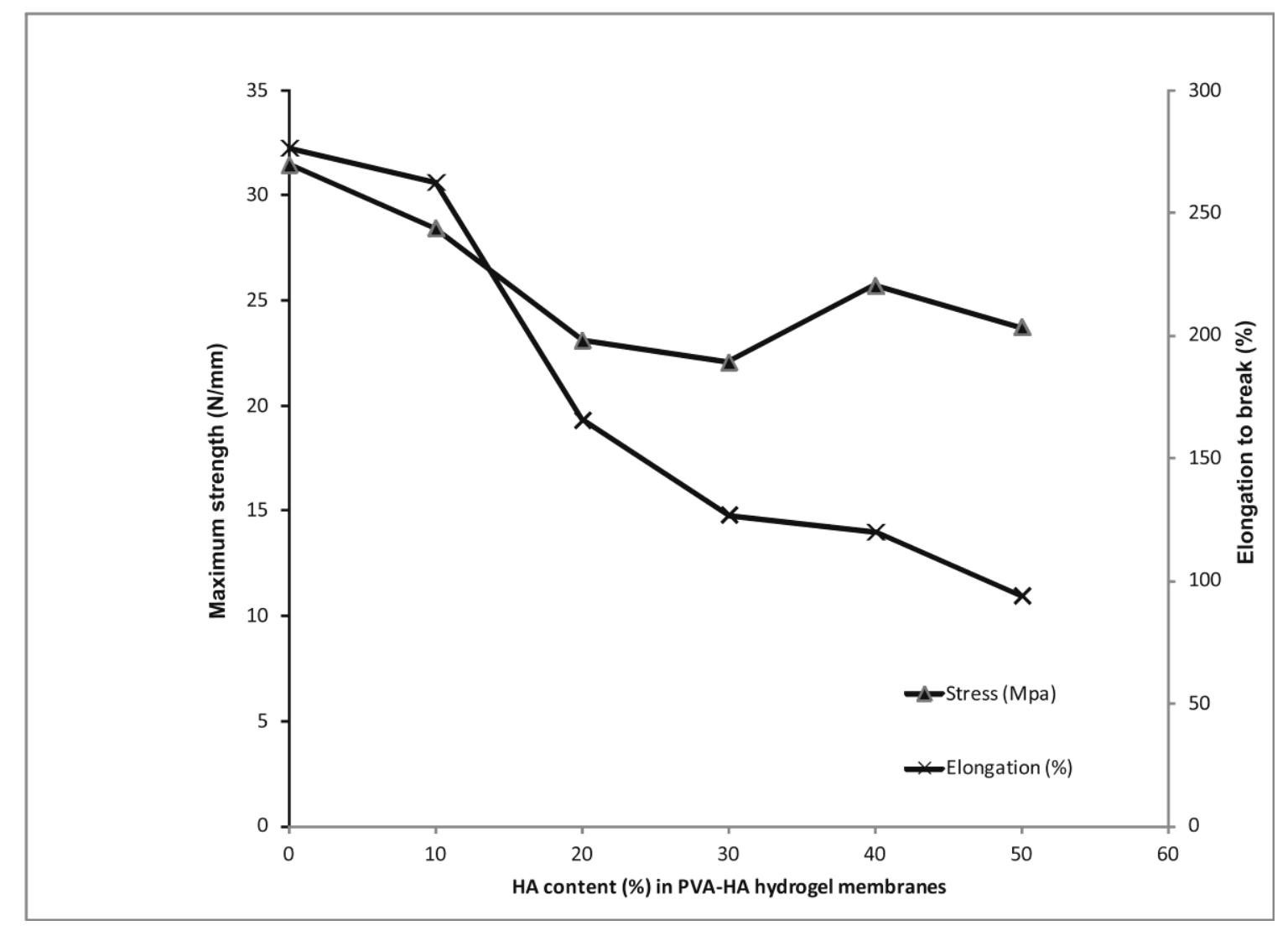

Fig. 2- Effect of hyaluronic acid contentes on mechanical properties of PVA hydrogel membrane.

\section{4-Protein adsorption}

The protein adsorption onto PVA-HA blend hydrogel membranes has been conducted via in vitro experiments. Fig.(3) shows the Protein adsorption of PVA hydrogel membrane at different Hyaluronic acid content in PBS. The results appeared that the Protein adsorption of PVA hydrogel membrane increases with increasing HA content in hydrogel membranes, the highest values of protein adsorption on PVA-HA surface have been cleared with the highest values of hydrophilic surface interaction due to the addition of HA contents. The blood compatibility of the hydrogel was evaluated by the amount of plasma protein adsorbed onto the hydrogel surface. When foreign material was placed in contact with blood, the adsorption of protein onto the surface occurred, leading to platelet adhesion and activation (Colm et al.,1982 and Burkatovskaya et al., 2006). Because the albumin adsorption on the synthetic surfaces could inhibit platelet activation, it did not promote clot formation. Generally, as the albumin/fibrinogen adsorption ratio was higher, the number of adhering platelets was lower (DionI $\boldsymbol{e t}$ al., 1993). Thus, HA gave less adhesion of platelets to artificial surfaces. This agrees the reported results by Kim et al. (2008) and Hwang et al. (2010), they revealed that the adsorption of protein increased with increasing blended alginate and dextran respectively in PVA hydrogels. 


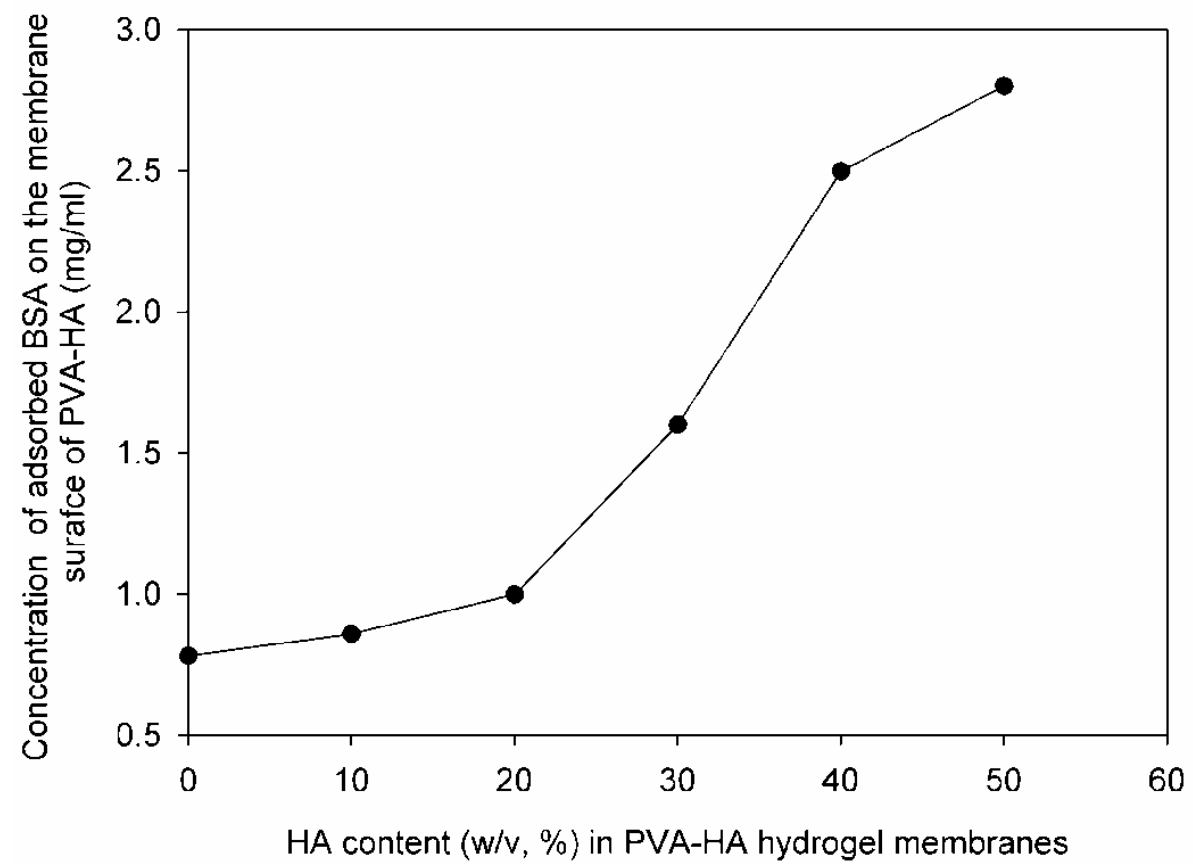

Fig. 3- Effect of Hyaluronic acidcontent on protein adsorption of PVA Hydrogel Membrane.

\section{5-Hydrolytic degradation}

The hydrolytic degradation of PVA hydrogel membrane at different hyaluronic acid content in Phosphate buffer saline(PBS) is showed in fig.(4). The results indicated that the hydrolytic degradation of PVA hydrogel membrane increases with increasing HA content in hydrogel membranes. This phenomenon can be ascribed to the degradation of PVA-HA hydrogel membranes that are predominantly the cleavage of cross-linking segments of PVA and is consistent with the fact that the degradation of PVA is quite slow (Takasu $\boldsymbol{e t}$ al., 2002), whereas the degradation of PVA-HA is quite high. In addition, as PVA and HA are nontoxic, the PVA-HA hydrogel and its degradation by-product might be expected to be nontoxic too. 


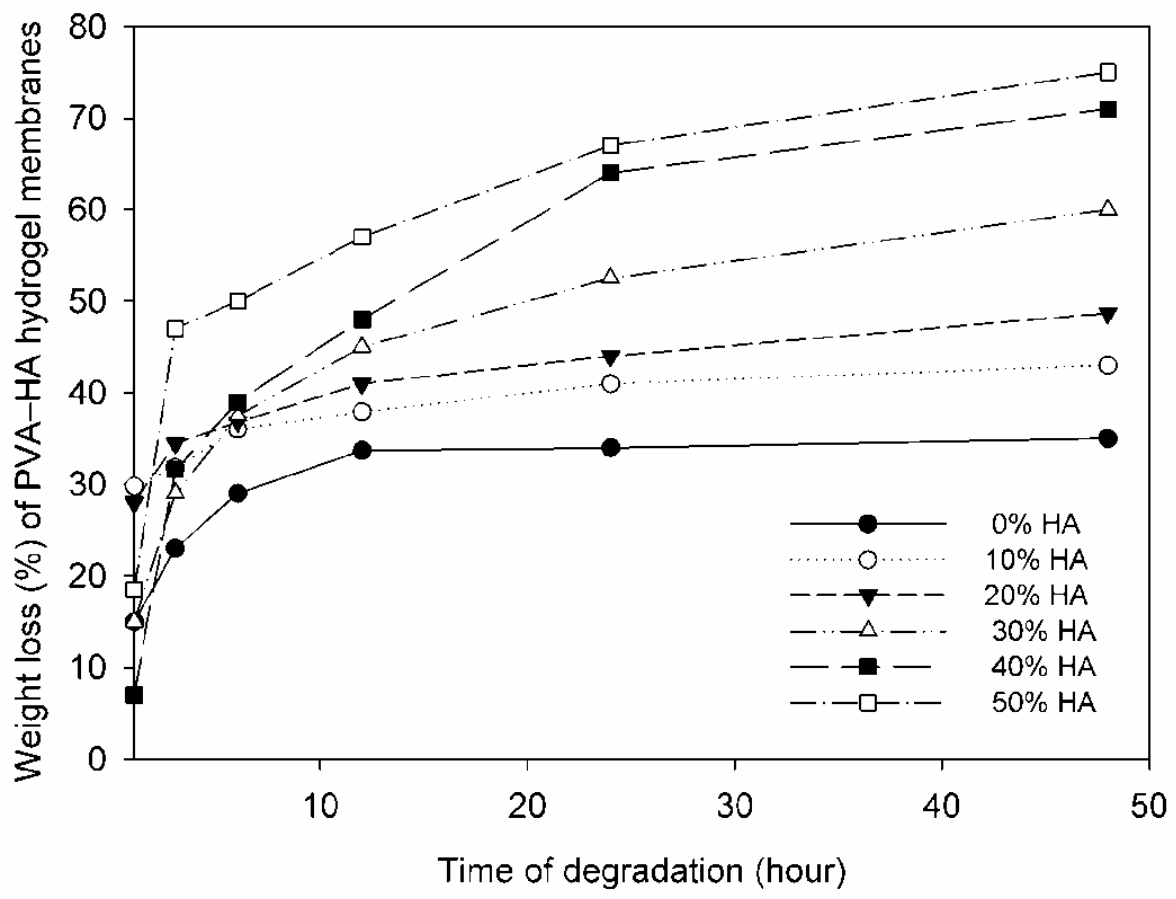

Fig. 4- Effect of HA contents on weight loss of the PVA-HA hydrogel membranes after different degrading times in phosphate buffer saline (PBS) $(0.1 \mathrm{M}, \mathrm{pH} 7.4$, at 37 $\left.{ }^{\circ} \mathrm{C}\right)$.

\section{CONCLUSION}

The PVA-HA blended hydrogels have been prepared by freezing-thawing technique as a physical cross-linking method. Each of swelling, hydrolytic degradation and protein adsorpition of PVA-HA hydrogel membranes increased with increasing HA content in hydrogels but both gel fraction and mechanical properties (tensile strength and elongation at break) decreased with increasing HA content in hydrogels. Then the addition of HA to PVA hydrogels is expected to improve the benefit of hydrogel membrane for biomedical applications.

\section{REFERENCES}

Abou El-Enin, M. A. E.(2013): Design and evaluation of some wound dressings with Antimicrobial Properties. A thesis of Msc., Tanta University : 117 pp.

Ajji, Z.; Othman, I. and Rosiak, J.M. (2005): Production of hydrogel wound dressing using gamma radiation. Nucl Instrum Methods Phys Res: Sect B. 229:375-380.

Alencar, D.Q.H.; Humberto, G.F.; Gustavo, A.A.; Maria, M. F.; Antonio, L.B. and Julio, S.R.(2003): Development of new hydroactive dressings based on chitosan membranes: characterizations and in vivo behavior. J. Biomed. Mater. Res. 64A, $147-154$. 
Berger, J., Reist, M., Mayer, J. M., Felt, O., \&Gurnyb, R. (2004): Structure and interactions in chitosan hydrogels formed by complexation or aggregation for biomedical applications. European Journal of Pharmaceutics and Biopharmaceu-tics, 57, 3552.

Briscoe, B.; Luckham, P. and Zhu, S. (2000): Polymer 41 : 3851-3860

Burkatovskaya, M.; Tegos, G. P.; Swietlik, E.; Demidova, T.N.; Castano, A. and Hamblin, M.R.(2006): Use of chitosan bandage to prevent fatal infections developing from highly contaminated wounds in mice. Biomaterials.27:4157-64.

Candy, T. and Sharma, C.P.( 1990): Chitosan as a biomaterial. Biomater. Artif.Cells Artif.Organs. 18, 1-24.

Coleman, D. L.; Gregonis, D.E. and Andrade, J.D.(1982): Blood materials interactions: the minimum interfacial free energy and the optimum polar/apolar ratio hypothesise. J Biomed Mater Res. 16:381-98.

Dai, S., \&Barbari, T. A. (1999): Hydrogel membranes with mesh size asymmetry based on the gradient cross-linking of poly(vinyl alcohol). Journal of Membrane Science, $156,67-79$.

De Jong, S. J., van Eerdenbrugh, B., van Nostrum, C. F., Kettenes-van den Bosch, J. J., \&Hennink, W. E. (2001): Physically cross-linked dextran hydrogels by stereocomplex formation of lactic acid oligomers: Degradation and protein release behavior. Journal of Controlled Release, 71, 261-275.

Dion, I.; Baquey, C.; Havlik, P. and Monties, J.R.(1993): A new model to test platelet adhesion under dynamic conditions. Application to the evaluation of a titanium nitride ccoating.Int J Artif Organs. 6:545-50.

Hassan, C. M., \&Peppas, N. A. (2000): Structure and morphology of freeze/thawed PVA hydrogels. Macromolecules, 33, 2472-2479.

Hennink, W. E., De Jong, S. J., Bos, G. W., Veldhuis, T. F. J., \& van Nostrum, C. F. (2004): Biodegradable dextran hydrogels cross-linked by stereocomplex formation for the controlled release of pharmaceutical proteins. International Journal of Pharmaceutics, 277, 99-104.

Hong, S.R.; Lee, S.J.; Shim, J.W.; Choi, Y.S.; Lee, Y.M.; Song, K.W.;Park, M.H.; Nam, Y.S. and Lee,S.I. (1993): Study on gelatin-containing artificial skin IV. Biomaterials 14, 2777-2783.

Hwang, M.R.; Kim, J.O.; Lee, J.H.; Kim, Y.; Kim, J.H.; Chang, S.W.; Jin, S.G.; Kim, J.A.; Lyoo, W.S.; Han, S.S.; Ku, S.K.; Young, C.S. and Choi, H.G.(2010): Gentamicin-loaded wound dressing with polyvinyl alcohol/dextran hydrogel: gel characterization and in vivo healing evaluation. AAPS Pharm. Sci. Technol. 11 (3), 1092-1103.

Kim, J.O.; Park, J.K.; Kim, J.H.; Jin, S.G.; Yong, C.S.; Li, D.X.(2008): Development of polyvinyl alcohol-sodium alginate gel-matrix-based wound dressing system containing nitrofurazone. Int JPharm.359:79- 86.

Korsmeyer, R., \&Peppas, N. A. (1981): Effect of the morphology of hydrophilic polymeric matrices on the diffusion and release of water soluble drugs. Journal of Membrane Science, 9, 211-227. 
Laurent,T.C.; Laurent,U.B.G.and Fraser,J.R.E.(1995): Functions of hyaluronan, Ann. Rheum. Dis. 54 : 429-432.

Lin, W.C.; Yu, D.G. and Yang, M.C.(2006): Blood compatibility of novel PGA (poly glutamic acid)/poly vinyl alcohol hydrogels. Colloids Surf. B Biointer. 47, 4349.

Long ,Z.;Hiroshi, M.;Maolin ,Z.;Fumio ,Y.;Naotsugu ,N. and Tamikazu, K.(2003): Synthesis of antibacterial PVA/CM-chitosan blend hydrogels with electron beam irradiation. Carbohydrate Polymers 53 : 439-446.

Maolin, Z.; Fumio,Y.; Tamikazu,K. and Kamaruddin,H. (2002): Synthesis of PVA/starch hydrogel by irradiation. Carbohydrate polymers 50:295-303.

Molina, I., Suming, L., Martinez, M. B., \&Vert, M. (2001): Protein release from physically cross-linked hydrogels of the PLA/PEO/PLA triblock copolymer-type. Biomaterials, 22, 363-369.

Okamoto, Y.; Minami, S. and Matuhashi, A.(1992): Application of chitin and chitosan in small animals. In: Brine, C.J., S and ford, C.J., Zikakis, J.P.(Eds.), Advances in Chitin and Chitosan. Elsevier, New York.

Park, K. R., \& Changnho, Y. (2003): Synthesis of PVA/PVP hydrogels having two layer by radiation and their physical properties. Radiation Physics and Chemistry, 67, $361-365$.

Peppas, N. A. (1975): Turbidimetric studies of aqueous poly(vinyl alcohol) solutions. Macromolecular Chemistry, 176, 3433-3440.

Peppas, N. A. (1987): Hydrogels in medicine in pharmacy. Boca Raton, FL: CRC Press., pp. $1-48$.

Peppas, N. A., \& Benner, R. E. (1980): Proposed method of intracordal injection and gelation of poly(vinyl alcohol) solution in vocal cords: Polymer considerations. Biomaterials, 1, 158-162.

Peppas, N. A., \& Scott, J. E. (1992): Controlled release from poly(vinyl alcohol) gels prepared by freeze-thawing processes. Journal of Controlled Release, 8, 95-100.

Peppas, N.A. and Stauffer, S.R. (1991): Reinforced uncross-linked poly(vinyl alcohol) gels produced by cyclic freezing-thawing processes: a short review. J. Control. Rel. 16: 305-310.

Queiroz, A.C.; Santos, J.D.; Monteiro, F.J.; Gibson, I.R. and Knowles,J.C.(2001): Adsorption and release studies of sodium ampicillin from hydroxyapatite and glass-reinforced hydroxyapatite composites. Biomaterials 22 (11): 1393-1400.

Rosiak, J.M.; Rucinska-Rybus, A. and Pekala,W.(1989): Method of manufacturing of hydrogel dressings. Patent USA, No.4, 871: 490.

Rosiak, M.T.; Darmawan, D. and Zainuddin, S.(2001): Irradiation of polyvinyl alcohol and polyvinyl pyrrolidone mixed hydrogel for wound dressing. Radiat. Phys. Chem. 62: 107-113.

Saettone,M.F.; Monti, D.; Torracca,M.T. and Chetoni,P.(1994): Mucoadhesive ophthalmic vehicles: evaluation of polymeric low-viscosity formulations, J. Ocular Pharm. 10 :83-92. 
Takasu ,A.; Itou, H.; Takada, M.; Inai, Y and Hirabayashi, T.(2002): Polymer ;43:22731.

Teramoto, N., Saitoh, M., Kuroiwa, J., Shibata, M., \&Yosomiya, R. (2001): Morphology and mechanical properties of pullulan/poly(vinyl alcohol) blends cross-linked with glyoxal. Journal of Applied Polymer Science, 82, 2273-2280.

Van Tomme, S. R., van Steen bergen, M. J., De Smedt, S. C., van Nostrum, C. F., \&Wim, E. (2005): Self-gelling hydrogels based on oppositely charged dextran microsphere. Biomaterials, 26, 2129-2135.

Wensheng, C. and Ram, B.G. (2002): "Hydrogels", Kirk-Othmer Encyclopedia of Chemical Technology.

Xiao, C. and Zhou, G.(2003): Synthesis and properties of degradable poly(vinyl alcohol) hydrogel. Polym.Degrad. Stab. 81: 297-301.

Yang, X.; Liu, Q.; Chen, X.; Yu, F. and Zhu, Z.(2008): Investigation of PVA/ws-chitosan hydrogels prepared by combined gama-irradiation and freeze-thawing. Carbohydr. Polym. 73: 401-408.

Yokoyama, F., Masada, I., Shimamura, K., Ikawa, T., \&Monobe, K. (1985): Morphology and structure of highly elastic poly vinyl alcohol) hydrogel prepared by repeated freezing-and melting. Colloid Polym. Sci., 264, 595-601.

Yoshii, F., Zhanshan, Y., Isobe, K., Shinozaki, K., \&Makuuchi, K. (1999): Electron beam crosslinked PEO and PEO/PVA hydrogels for wound dressing. Radiation Physics and Chemistry, 55, 133-138. 